\title{
DISCURSO, IMPRENSA E REPRODUÇÃO DA DISCRIMINAÇÃO
}

\section{Belmira Magalhães (UFAL)}

Este estudo ${ }^{1}$ faz parte do projeto $O$ discurso sobre o oprimido e a representação da opressão, integrado à linha de pesquisa em Análise do Discurso, da UFAL, que analisa discursos sobre o oprimido, procurando perceber os efeitos de sentido e os silenciamentos capazes de produzir e reproduzir o imaginário que contribui para a manutenção da opressão.

Partimos de duas premissas iniciais para a realização da pesquisa: a midia é uma das fontes mais importantes de formação do imaginário colctivo em um mundo em que o discurso sobre assume maior importância do que o fato em si; os programas e suplementos jornalísticos dedicados ao publico feminino surgem a partir do movimento feminista dos anos 60 e se propõem discutir a especificidade desta parte da população concedendo voz à própria mulher.

A imprensa buscava, e em alguns casos, ainda busca aparecer ao público como neutra, demonstrando un lugar de fidelidade aos fatos. Hoje, no entanto, a possibilidade de posicionamento diante dos fatos, o jornalismo de opinião, se coloca, há uma explicitação do lado interpretativo da notícia. Os cadernos específicos vêm ao encontro dessa nova perspectiva.

O Caderno Mulher, em princípio, é leito para promover uma filtragem e veicular notícias que ofereçam ao público-alvo aquilo que presumivelmente ele gostaria de ler. Os dois cadernos analisados (Gazeta de Alagoas e Jornal do Brasil) surgem depois do chamado novo movimento feminista, que no Brasil tem sua maior força nas décadas de $70 \mathrm{e} 80$ do século passado. Fica evidenciado o surgimento de um novo grupo leitor de jornais, para o qual são dirigidas essas publicações.

Parte deste texto foi apresentada no I Congresso e IV Colóquio da Associação Latinoamericana de Estudos do Discurso. Recife. Setembro/2001. 
Segundo Mariani (1998), o discurso jornalístico pode ser considerado como discurso sobre, isto é, ele transforma em objeto aquilo sobre o qual fala, produzindo assim um efeito de objetividade passível de conduzir a um efeito de imparcialidade, principalmente quando o enunciador é transformado em observador. Na verdade, há uma produção de sentido autorizando o sujeito do discurso, pela competência e rigor do fato narrado, a produzir juízos, que não serão de valor, mas de explicação dos fatos.

Os discursos sobre são discursos que atuam na institucionalização dos sentidos, portanto, no efeito de linearidade e homogeneidade da memória. [...] De modo geral representam lugar de autoridade em que se efetua algum tipo de transmissão de conhecimento, já que o falar sobre transita na co-relação entre o narrar/descrever um acontecimento singular, estabelecendo sua relação com um corpo de saberes já reconhecido pelo interlocutor (Mariani,1998:61).

No entanto, pode-se enfatizar que, mesmo a materialidade discursiva apresentando-se como um lugar de neutralidade ideológica, e seus efeitos de sentido sendo percebidos como composições conciliatórias dos sujeitos do discurso, há sempre uma vinculação a uma formação ideológica da sociedade. Os discursos são práxis sociais e, por isso, só podem ser explicados através do desvelamento das relações sociais que lhes determinam e que estão representando. O sentido é socialmente construido pelo homem para o homem, para si e para os seus semelhantes (Lukács, 1997:70).

O sujeito do discurso escolhe, mas não o que quer, independente do lugar social que ocupa (formação ideológica) e do tipo de discurso que elabora (formação discursiva). No caso das escolhas discursivas tem-se uma ligação direta com a necessidade de transformar a realidade, no que se refere principalmente à transformação da consciência do outro ou a sua própria. $\mathrm{Na}$ construção discursiva, o sujeito é socialmente determinado e está subsumido ao código da linguagem, exercendo, então, a liberdade a partir desses determinantes. Ainda segundo Lukács:

Quanto maior for o conhecimento das cadeias causais que operam em cada caso, tanto mais facilmente podem ser transformadas em cadeias causais postas, tanto mais seguro é o dominio do sujeito sobre elas, ou seja, a liberdade que ele pode ter (Lukács, 1997:75). 
Nesse sentido é que Lukács afirma que o discurso se inscreve diretamente no âmbito das teleologias secundárias, cujo objetivo direto é a relação entre os homens ${ }^{2}$, e, no caso das sociedades contemporâneas, cuja complexidade social cria uma segunda natureza, a prática discursiva assume uma relevância fundamental nos caminhos escolhidos pela humanidade. A transformação do curso dos acontecimentos, que possui uma lógica própria independente das consciências individuais, ocorre, contraditoriamente, através de sujeitos que necessitam ter conhecimento da essencialidade dessas contradições sociais para que venham a possuir a chance de imprimir suas marcas na objetividade.

Ao elaborar um discurso, o sujeito tem uma intencionalidade que se refere diretamente ao objetivo de sua ação; no entanto, não tem controle sobre a eficácia e nem dos caminhos possíveis de ser efetivados a partir da coletivização do discurso. É preciso não esquecer que, mesmo com a complexidade social e o crescente peso das decisões subjetivas nas alternativas postas e escolhidas, a subjetividade deve ser sempre entendida como um fenômeno social.

Todas as valorações que aparecem nestas decisões subjetivas estão ancoradas na objetividade social dos valores, no significado destes para o desenvolvimento objetivo da espécie humana, e tanto a sua relação ou contraposição a valores, quanto a intensidade e duração de sua eficácia são, em última análise, resultado deste processo social objetivo (Lukács,1997:86).

Nas sociedades de classe modernas, o discurso dominante (liberal) não pode explicitar o cerne das contradições sociais, embora tenha de procurar dizer a realidade. Esse duplo aspecto faz o discurso dominante se constituir primeiro para silenciar e só secundariamente para dizer. O fundamento ideológico da sociedade que se instaura com a modernidade, como vimos, é a negação dos privilégios sociais, a busca da igualdade e da liberdade para todos.

Nesse sentido, podemos afirmar, para o caso da sociedade capitalista, que o silêncio é o fundante do seu discurso, na medida em que, diferentemente das anteriores, as diferenças de classes devem ser justificadas. O silêncio de que falamos aqui não é ausência de sons ou

2 Para maior desenvolvimento dos conceitos de teleologia primária e teleologia secundária ver Vaismann (1989). 
de palarras. Trara-se do silencio fundador; ou fundante de toda significaçĩo. Cf. ORLANDI, 1993:70.

Pode-se sintetizar essa contraditoriedade explicitada acima. afirmando que todo e qualquer discurso criado numa sociedade desse tipo, por menos que diretamente esteja vinculada à estrutura de classe. ocupará um dos lados do conflito: continuará silenciando a real estrutura da sociedade, ou explicitará esse silenciamento estrutural. $\mathrm{Na}$ verdade, o jogo das ideologias (dominante e dominada) se faz a partir da lógica dialética, cuja premissa é o apagamento ou o desvelamento das diferenças de classe.

Diferente era a situação em outros momentos históricos. Embora a escravidão tenha ocorrido em periodos diferentes do caminhar da humanidade, apresenta características semelhantes quando se consideram períodos tão distintos, como a Antigüidade grega e a modernidade. Segundo Aristóteles, na Politica (1996). o escravo possui uma natureza diferente da do senhor, sendo esse o motivo que o faz intrinsecamente um escravo. mesmo quando essa polencialidade não chegue nunca a se tornar um fato (ato).

Para esse autor, um escravo é um instrumento dotado de voz. incapaz de fazer uso pleno da razão e, por isso, precisa ser comandado e protegido. Sintetizando, a natureza do escravo o faz diferente e inferior ao senhor. não tendo como tornar essa diferença uma igualdade.

Paralelamente, Aristóteles alirma que só o homem livre e adulto pode ser cidadão, excluindo da cidadania tanto o escravo, como a mulher c os seres em desenvolvimento (as crianças),assim como aqueles que já ultrapassaram certa idade (os idosos) e, coerentemente, os estrangeiros. Veriticamos que. desde a Antigüidade, a mulher é, cm certa medida, nivelada ao escravo. Essa afirmação fica mais nitida ainda quando se toma como referência a noção de família, que, para os gregos, está associada à noção de um espaço (oikós) e de un dono (despóless). ( ) chefe da familia possui uma autoridade pessoal e arbitrária sobre todos os membros que habıtam o oikós, nas palavras de Chaú( 1994):

Na familia, a autoridade é exercida pelo chefe da familia segundo a vontade pessoal, individual e arbitrária desse chefe, cuja única lei ou regra é sua vontade e seus próprios interesses. A autoridade do despótes é uma autoridade privada, é o poder de vida e morte inquestionado que detém sobre todos os membros da familia, e o poder absoluto de dispor de todos os bens móveis e imóveis da familia.(p.325) 
Essa situação é transplantada para a realidade brasileira com a adoção do trabalho escravo no início da colonização; resguardadas as condições históricas da modernidade, as unidades produtoras rurais brasileiras podem ser consideradas como um oikós na medida em que o poder político central, que traz intrínseca a noção de público e de bem comum, tem muito pouco acesso às decisões dos senhores rurais em relação a seus escravos, a suas mulheres, a sua prole e a seus agregados.

Para justificar a dependência feminina, o mundo grego constrói uma argumentação baseada na esfera orgânica, pois para Aristóteles ${ }^{3}$ todo ser vivo tem alma, mas as almas se diferenciam. A alma vegetal é mais simples, a animal um pouco mais complexa e a alma do homem é completa, pois agrega a função mais importante, que é a razão. O macho é o princípio gerador motor, a fêmea o princípio material; o que define a fêmea é o útero, que, segundo ainda o filósofo. não produz semente fértil, mas se constitui no lugar que alimenta e conserva o germe colocado pelo homem. Sintetizando a concepção grega da fêmea, pode-se afirmar com Pratres e Silva(1991) que:

A fêmea é o resultado de uma mutilação natural do macho, ou seja, a fêmea é um macho incompleto ou inacabado. [...] A fêmea é como um macho incompleto e seu órgão gerador, o útero, só produz semente imperfeita, a qual falta uma coisa, a principal: o principio da alma (p.54).

No período colonial brasileiro, a associação entre o escravo e a mulher em geral ainda pode ser feita. Embora o preconceito racista se restrinja- às mulheres negras, a todas são atribuidas características que se assemelham ao padrão de discriminação que afetava as mulheres gregas: a necessidade de um despótes para guiar-lhes o caminho.

Como salientamos, as sociedades de classes que precederam o capitalismo defendiam as diferenças sociais baseadas em um princípio de desigualdade intrínseca entre os seres humanos. Essa desigualdade regia a legalidade dessas sociedades, sendo explicitada em todos os discursos do cotidiano ao teológico. A lógica capitalista, ao contrário, necessita de seres livres que entrem em relação a partir de consentimentos mútuos, pois que senhores de suas ações. A individualidade e a igualdade de

Para o desenvolvimento desse tema através do estudo da tragédia grega, ver Prates e Silva (1991). 
oportunidade marcam a ideologia da sociedade moderna, e as desigualdades são encaradas como intrínsecas às individualidades diferentes, ou como desvios a ser corrigidos e/ou combatidos.

No entanto, o tratamento dado às mulheres dentro da esfera familiar, independente do grau de fortuna, é sempre o de alguém que necessita ser cuidado, conduzido. Na verdade, a sociedade brasileira é formada por uma cultura da exclusão, calcada nas relações de produção que determinam quem e quantos podem ter acesso aos bens, ao poder, promovendo de forma diferente, mas sempre tendo por pressuposto que não pode haver uma distribuição igualitária dos bens materiais e simbólicos.

\section{OS CADERNOS MULHER}

Os dados jornalísticos aqui estudados demonstram que a chave para a compreensão da problemática feminina reside na ideologização das capacidades de gestar e aleitar, isto é, no conceito construído socialmente sobre a maternidade. Só o entendimento desse deslocamento produzido ideologicamente explica a força da ideologia patriarcal no mundo contemporâneo.

Os cadernos Mulher, da Gazeta de Alagoas e do Jornal do Brasil $^{4}$, têm a seguinte estrutura:

\begin{tabular}{|l|l|}
\hline \multicolumn{1}{|c|}{ Gazeta de Alagoas } & \multicolumn{1}{|c|}{ Jornal do Brasil } \\
\hline Capa: fotografia colorida de uma & Capa: uma reportagem com \\
mulher. & fotos \\
Colunas: & Colunas: \\
Moda / Beleza & Mulher integral \\
Opinião & Planeta mulher \\
Literatura & Auto-retrato \\
Interior / Design & Reportagem da página central \\
Arte/ Cultura & Contra-capa reportagem \\
Comportamento & \\
Saúde & \\
Reportagem com a mulher da capa & \\
Contra-capa: receitas & \\
\hline
\end{tabular}

4 Os dois cadernos analisados são publicados somente aos sábados. 
A análise do quadro reflete a diferença de proposta dos dois jornais. No jornal Gazeta de Alagoas a coluna Opinião funciona como editorial do Caderno Mulher. Em um ano - 46 cadernos analisados apenas 22 matérias discorriam sobre a temática da condição feminina; destas nove se referiam diretamente à saúde da mulher, sendo quatro com ênfase na questão da AIDS; duas tratavam das mudanças de relacionamento entre os sexos; duas sobre violência (estupro e violência doméstica); uma sobre aborto, duas sobre datas comemorativas ( 8 de março e aniversário do caderno); uma sobre a participação das mulheres numa manifestação local que culminou com a renúncia do governador; uma sobre a participação feminina como mão-de-obra no Mercosul; uma sobre a proposta de Pequim e o Fórum da violência; uma sobre mutilação de meninas no Senegal; uma sobre paternidade responsável; e outra sobre a sem-terra que posou nua para uma revista masculina.

As demais matérias (50\%) são de assuntos gerais como, por exemplo, a poluição das lagoas, a crise financeira do Estado, os problemas no/do trânsito.

Analisando esses dados pelo caráter específico esperado de um caderno destinado ao público feminino, percebe-se o afastamento da orientação editorialista daquelas questões mais diretamente relacionadas à mudança do papel da mulher na sociedade pós-novo movimento feminista, desperdiçando assim um espaço que poderia servir ao fomento da discussão e não necessariamente à concordância com o ideário feminista. Tomemos algumas dessas matérias mais detidamente.

No editorial de 2 de maio de 1998, com o título Cultura e mutilação, há uma referência aos perigos da retirada do clitóris a que se submetem as meninas no Senegal. Após afirmar que esse ato compromete, "de forma irreversível, a satisfação sexual da mulher", o discurso passa a enumerar outras conseqüências dessa violência:

Além disso, existem danos à saúde, como hemorragias, até com a morte, infecções ginecológicas, urinárias, dores na vagina e, óbvio, traumas psicológicos.

Em nenhum momento do editorial há referência à discussão que vem sendo travada há anos sobre a relação entre culturas singulares e suas tradições e os direitos universais da humanidade. 
A polêmica não foi resolvida, pois entre outros aspectos é perpassada pela questão da autonomia dos países. O que causa espanto é o tratamento que o jornal dedica ao tema, apenas listando as conseqüências como se fizessem parte de um rol sem nenhuma hierarquia, o que é ressaltado pela expressão além disso e, o que é mais grave, considerando uma polêmica deste porte como coisa óbvia, o que reforça a afirmação de que os assuntos são tratados de forma inteiramente superficial.

As matérias sobre saúde estão, em sua maioria, ligadas à reprodução e à maternidade, com ênfase no papel da mãe como protetora dos filhos contra a AIDS: Mães se cuidem para que seus filhos não se contaminem.

Em 10 de maio de 1998 é discutida a gravidez por estupro. Afirma-se que, pela lei, a mulher pode optar pela interrupção da gestação nessas condições. Há a apresentação dos resultados de uma pesquisa realizada pelo Conselho Nacional dos Direitos da Mulher e pelo Programa de aborto legal do Hospital de Jabaquara, em São Paulo, onde as mulheres que realizaram aborto afirmam não se arrepender de ter tomado tal decisão.

É interessante ressaltar que no mesmo dia desse editorial há uma reportagem com um pároco, com o título Maria, mãe de todas as mães, onde o religioso acentua a importância de Maria para todos os homens e, conseqüentemente, da maternidade. "Ela é o carisma feminino da cristandade e o símbolo mundial do dom da maternidade".

No mesmo caderno afirma-se que as mulheres estupradas não se arrependem dos abortos a que se submeteram e que há um dom da maternidade capaz de redimir toda a humanidade. Como a Igreja Católica expressa largamente sua condenação a qualquer forma de aborto, embora no editorial não haja também uma condenação, mas uma informação com a frieza dos dados, a reportagem com o pároco acaba por fazer o papel de condenação dos atos daquelas mulheres.

Das duas matérias que se relacionam à violência contra a mulher, uma (13/9/98) se refere à "lentidão processual", que acaba por "inviabilizar os julgamentos", havendo uma crítica direta à justiça do Estado. A outra, que tem o título dormindo com o inimigo, dá conhecimento ao leitor/a de que as mulheres brasileiras têm mais 30\% 
de chances de ser assassinadas por parceiros e amigos do que por inimigos ou colegas de trabalho.

No mesmo dia é ressaltado o aumento da violência contra a mulher em Maceió, e, em entrevista com a delegada especial da mulher da cidade, esta declara: quando a violência contra a mulher está dentro de casa, os mais prejudicados são os filhos. Mais uma vez as marcas do corpo da mulher são apagadas pela função de mãe, pois, embora os filhos e a família em geral sejam afetados pela violência contra a mulher, ninguém mais do que ela sofre as conseqüências, até porque são elas que, além de sentir no corpo o peso da violência, sentirão na alma os traumas dos filhos.

$\mathrm{Na}$ sociedade urbaṇa contemporânea, três dimensões subsidiam a definição de família: a sexualidade, a procriação e a convivência. Completando essas dimensões, podemos afirmar que, na esfera simbólica, a família é o lugar da intimidade e da afetividade. No mundo urbano formam-se duas esferas bem diferenciadas:

1-o lugar da produção, do trabalho; o espaço da rua; o lado de fora;

2-o lugar da reprodução biológica, da afetividade, da família; o espaço da casa; o lado de dentro.

Há um rompimento com a noção de oikós, na medida em que a família não é mais uma unidade produtora. A reprodução social determina as tarefas necessárias à manutenção do sistema, agora executadas em espaços diferenciados: a reprodução biológica e cotidiana será realizada pela família no espaço da casa e a reprodução econômica e legal no espaço da rua, nas fábricas e órgãos públicos da administração e do poder.

Essas mudanças, no início, pouco alteraram as relações simbólicas familiares. Os homens continuam sendo os chefes da família, com poder de decisão sobre todos os assuntos, mesmo considerando que na maioria dos estudos realizados, há indicação de que poucos são os trabalhadores a conseguir, apenas com seu salário, manter a família. O trabalho dos filhos e até de filhas solteiras vem complementar a renda necessária/possível para a sobrevivência de todos. Às mulheres casadas cabem tarefas sempre efetuadas no âmbito doméstico (lavagem de roupa, doces, costuras etc.). Não há mudança no modelo familiar nem nas relações de gênero. 
Essa situação se desestabiliza quando as mulheres casadas passam a realizar tarefas fora do espaço da casa. Embora não haja redistribuição das tarefas e responsabilidades da reprodução cotidiana com os homens, só a ausência da esposa/mãe do espaço doméstico ameaça a estruturação familiar aparentemente perene.

Generaliza-se então a dupla jornada; a responsabilidade com os cuidados dos filhos não é repassada nem quando a família faz uso de creches e outros mecanismos, pois admitir que as tarefas de reprodução cotidiana não são eminentemente femininas seria considerá-las desvinculadas da natureza da mulher, o que proporcionaria um rompimento com a construção simbólica, que, desde a Antigüidade, afirma serem as funções do útero e da amamentação os únicos determinantes do lugar social feminino. Paralelamente, essa aceitação significaria a necessidade de visibilizar o trabalho doméstico e de computá-lo como horas gastas na manutenção da reprodução do sistema, o que acarretaria grandes perdas para a lógica do capital. ${ }^{5}$

Em síntese, o exame do conjunto do Caderno Mulher, da Gazeta de Alagoas, evidencia um reforço do lugar da mulher enquanto mãe e uma superficialidade no tratamento das outras questões de interesse específico. Com mais um exemplo salientamos o único texto sobre o aborto, surgido a partir de fato amplamente divulgado, relativo à gravidez de uma menina de 11 anos, cuja possibilidade de abortar foi contestada pela Igreja e por movimentos cristãos. O editorial enfatiza o fato clínico, os riscos à saúde da criança em uma gravidez e se direciona ao questionamento da impossibilidade de uma criança exercer a maternidade, pois estaria na hora de brincar de bonecas. A questão geral sobre o aborto é nomeada apenas para se referir ao fato de que não existe consenso.

O caminhar da humanidade tem sido sempre uma busca para além das leis biológicas e, paralelamente, principalmente nos últimos séculos, uma busca incessante de uma individuação que, ao mesmo tempo expressa uma sociabilidade e torna possível a realização de desejos individuais. A modernidade prometeu isso: no entanto, reduziu a individualidade à possibilidade de venda da força de trabalho em um mercado dominado pelo capital e com uma instituição jurídico-política que reafirma a supremacia de uma classe sobre as outras. ${ }^{6}$

\footnotetext{
5 Ver Chauí (1986).

6 Ver Marx (1995).
} 
Foram analisados 49 Cadernos Mulher do Jornal do Brasil. A coluna Mulher Integral representa o editorial, e durante um ano foram discutidos os seguintes grupos de assuntos:

TEMA

1- Idade/saúde/beleza/moda

2- Trabalho/carreira

3- Imagem da Mulher

4- Maternidade

5- Feminismo

6- Princesa Diana

7- Casamento

8- O cinema
FREQÜÊNCIA

17

Embora no caderno do JB todas as matérias dos editorialistas se dirijam ao público feminino, não há nenhuma reportagem sobre itens gerais, como no caderno da imprensa alagoana; aqui, a ênfase recai sobre as questões relacionadas ao corpo em geral e à aparência física em particular, ressaltando as novidades para a manutenção da beleza e as dificuldades em assumir a própria idade, numa proposta bastante ambígua, pois ao mesmo tempo que afirma ser "hora de contar a idade", no sentido de não esconder a própria história, sugere sempre formas de recuperar a juventude do corpo (novos cremes, plásticas, etc.), criando paralelamente o sentido de uma preocupação crescente com a idade expressa no número de matérias que se dedicam a esconder as marcas do tempo no corpo feminino.

Em relação à imagem feminina, tem-se também um discurso dúbio através do qual é ressaltada a necessidade de se tornar uma nova mulher, o que significa entrar no mercado de trabalho, competir com os homens, sem se tornar um deles; paralelamente é construída uma fala onde são ressaltados os benefícios de ficar em casa, tomando conta do lar: "a de que você que tanto trabalha sem remuneração, tem afinal, no calor do lar, no carinho dos filhos, no convívio mais estreito com as amigas algumas vantagens de inúmeras executivas de altos contra-cheques." 
O discurso faz uma comparação entre lar e trabalho, criando a seguinte dicotomia:

Trabalho sem remuneração mas carinho dos filhos, convivio estreito com as amigas.

Trabalho com altos contra-cheques mas sem carinho dos filhos nem convivio com as amigas.

Na verdade não há evidência de que as executivas não tenham filhos nem amigas; no entanto isto fica insinuado com a expressão algumas vantagens. E o dado mais importante é que se silenciam as vantagens de ser executiva com altos contra-cheques, reforçando o lugar da mulher que, mesmo sem nenhuma remuneração, está repleta de afetividade no calor do lar, enquanto as executivas estão só no frio de apartamentos vazios de afetividade.

Percebe-se que a partir de mecanismos lingüísticos produtores de efeitos de silenciamento, é realizado o jogo de produzir o dito, deixando implícito o não-dito e silenciando o impossível de ser explicitado, fazendo que o leitor/ouvinte tenha de, necessariamente, sair do discurso para compreender a dinâmica do próprio discurso, desvendando sua opacidade.

Em um editorial (21 de junho de 1997) está registrada uma crítica aos questionamentos feitos às mulheres sobre como elas conseguem conciliar carreira e rotina doméstica. Há um incentivo para que elas resistam até o dia em que a mesma pergunta seja dirigida aos homens: "mas não desistam: um dia, quem sabe, essa pergunta será feita aos homens".

A forma como é composta a materialidade discursiva transporta o discurso para um futuro distante, que pode não ser o das leitoras - um dia. Para deixar mais desanimadora a resistência à falta de uma realização próxima da igualdade é acrescida a possibilidade de esta nunca acontecer, pois a expressão quem sabe cria a dúvida sobre a possibilidade do surgimento desse novo tempo.

Corroborando a construção do discurso dúbio está a matéria veiculada na reportagem de página central do mesmo dia desse editorial. Em uma entrevista com uma bancária, é afirmado que

características da fisiologia feminina determinam e inibem o convivio social. Os papéis sociais são definidos ainda na gravidẹz. Angélica com suas duas filhas no colo diz: - alguém 
tinha que parar a carreira para cuidar delas - e fui eu. Optei por uma familia harmônica.

É interessante ressaltar que a afirmação acima salienta a existência de um problema real, a criação dos filhos, não aceita pela sociedade como tarefa coletiva mas da família, pela estrutura individualista e patriarcal de nossa sociedade. Sendo um problema particular, as famílias têm de procurar se adaptar, mesmo que isto implique momento de dificuldade financeira, abandono de emprego por parte da mulher.

Há uma naturalização explícita da gravidez, que passa a significar diretamente uma vocação para a maternagem caracteristicas biológicas determinam. O mesmo raciocínio dos gregos é utilizado para explicar a alma menor da mulher, isto é, é da natureza da mulher, algo que não pode ser mudado. Por isso o editorial duvida que um dia, quem sabe, não se pergunte só à mulher sobre a relação carreira/rotina doméstica.

$\mathrm{Na}$ verdade não há opção alguma, como afirma a ex-bancária entrevistada, mas uma imposição de natureza biológica. Embora a modernidade, como foi dito, traga para o indivíduo a idéia de que pode fazer escolhas que só tenham a ver com a sua opção pessoal, como agora está sendo veiculado pelo discurso empresarial que disponibiliza para o trabalhador e para o consumidor um cardápio de opções a ser escolhidas dependendo do gosto de cada um. No entanto, o que ocorre é apenas a ilusão simbólica de escolhas pré-determinadas socialmente pelas relações de exploração de classe, que perpassam todas as formas de convívio social.

Aqui também, a idéia fixada na expressão da ex-bancária, que acredita ter feito uma opção consciente, já está inscrita na sociedade como forma primordial do papel feminino, que tem de fazer cumprir sua função biologicamente determinada; da mesma forma que o trabalhador tem de se contentar com as benesses oferecidas pelo patrão ou perder o emprego, e o consumidor que escolhe dentro das possibilidades do seu poder de compra entre os produtos que o mercado estabeleceu como prioridade para aquele momento.

Enfim o Jornal, através do uso da fala da bancária e da interpretação do repórter, novamente não se compromete com nenhuma posição: a mulher foi quem escolheu conscientemente ficar em casa cumprindo sua função primordial - a maternidade. 
Na reportagem central do dia 27 de setembro de 1997 são enaltecidas características ditas essencialmente femininas.

As empresas descobrem que a função de ombudsman precisa de caracteristicas muito femininas: paciência e sensibilidade.

$\mathrm{Na}$ verdade exaltam-se características bastante discutíveis: a paciência, que fez, e ainda faz, com que mulheres se conformem com situações aviltantes, tanto no espaço doméstico como no espaço de trabalho, e a sensibilidade, que normalmente é vista como empecilho ao bom desempenho racional necessário no espaço da rua. Reforçando este tipo de matéria que não discute os fatos, apenas os noticia com a aparente neutralidade própria da reportagem, está o editorial de 4 de outubro de 1997, que elogia o teatrólogo Nelson Rodrigues, mas acentua existir um residual em suas obras que acaba por prejudicar a mulher: aquele comentariozinho de que as mulheres gostam de apanhar. Sem uma análise contextualizada da obra, e dizendo que a afirmação do dramaturgo é apenas um comentariozinho, cria-se uma dubiedade fazendo que o fato de gostar de apanhar integre as características femininas.

A feminização do trabalho é apontada com uma conquista das mulheres, sem nenhum questionamento do porquê de características como sensibilidade e paciência estarem sendo requeridas para determinadas funções, no momento histórico em que a classe trabalhadora tenta não perder conquistas conseguidas em mais de um século de luta e o desemprego ronda o sono das famílias.

No Caderno Mulher, de 25 de outubro de 1997, após ressaltar o fato de a presidência da Academia Brasileira de Letras ter sido assumida, pela primeira vez em sua história, por uma mulher, a escritora Nélida Piñon, é feito o seguinte comentário:

Ela assumiu a presidência da $A B L$, neste ano do centenário, como uma simpática dona de casa e eficiente anfitriã.

Embora em seguida descreva os projetos que a escritora tem para sua gestão, é sintomático e depreciativo que o jornal aponte para o papel de dona-de-casa quando uma mulher assume pela primeira vez a casa de Machado de Assis.

O discurso que salienta a necessidade de estar atenta ao mercado, enfatizando ainda o não-abandono da lida doméstica, e nunca se referindo à divisão de tarefas nem mesmo ao auxílio dos 
filhos, isto é, à participação de toda a família para o surgimento de uma nova mulher, cria um efeito de divisão interna que acompanhará sempre o cotidiano da mulher moderna. Na verdade, a mensagem sugere necessidade de mudanças do comportamento feminino sem alterações substanciais na estrutura familiar e, nela, que o papel da mulher permaneça essencialmente o mesmo.

No jornal do mesmo dia da reportagem anterior, o editorial critica a máxima segundo a qual "por trás de um grande homem existe uma mulher", caracterizado como "chato de ouvir desde pequenina, fazendo que haja, por parte da mulher, uma internalização como personagem coadjuvante". A reportagem termina afirmando que "hoje em dia as coisas mudaram". Ao se analisarem os cadernos em sua integralidade pode-se concluir com a mesma pergunta que a editorialista faz: Será?

Com a reportagem anteriormente analisada não se poderia pensar que as mulheres estão sendo chamadas para ocupar os cargos, antes só exercidos por homens, quando há necessidade de arrumar a casa ou ter paciência para com os colegas, já que os homens têm mais o que fazer do que se preocupar com estas coisas menores. Fica então o questionamento: por que o jornal não aproveitou para salientar a obra da escritora, agora presidente, que mergulha nas relações entre os sexos, aprofundando a visão sobre as contradições da vida moderna?

Na discussão das temáticas do Jornal, o discurso feminista é o grande ausente. Em um editorial que ressalta a importância das comemorações do dia internacional da mulher (8 de março), é enfatizada a importância do papel da imprensa, em especial da imprensa específica, na divulgação das "coisas de mulher", em detrimento dos movimentos que se preocupam em conscientizá-la através de ideário próprio e de manifestações:

Pode parecer que não, mas lembrar a mulher com um dia no calendário anual, faz mais por ela nos outros dias do ano do que uma série de atos isolados de conscientização politica. Porque quanto mais os temas e assuntos femininos ganharem espaços e visibilidade neste momento em que, finalmente, ela começa a conquistar os direitos e deveres até então estritamente masculinos.

Como se vem demonstrando, os temas femininos tratados pelo Caderno Mulher, do Jornal do Brasil são beleza, culinária, saúde e discursos dúbios sobre os novos tempos. A única feminista a merecer 
destaque em um ano de publicação é nomeada "feminista tranqüila" pela reportagem, para referir-se à serenidade de Glória Steneim. Na verdade a editoria não está dizendo, mas deixando implícito que as feministas não são tranqüilas nem possuem serenidade no tratamento de suas questões, talvez por isso não mereçam ser motivo de reportagem. Outra a merecer o título de feminista é a gatinha Mulan do desenho animado. Evidencia-se que em relação ao ideário do feminismo e às próprias feministas há apenas criticas e ausências.

O novo movimento feminista vem sendo questionado desde sua origem, em todo o mundo, como uma ameaça aos valores estabelecidos. A desestabilização da família, a má educação dos filhos são algumas das conseqüências apontadas pelos críticos desse movimento. Na representação artística, essa problemática tem sido exaustivamente discutida (cinema, TV, teatro, ficção, humorismo). Paralelamente, a literatura que discute teoricamente o assunto cresce a cada dia. Há veiculação de um imaginário representado por um discurso moderno em sua forma, que reforça a necessidade de mudanças das relações entre os sexos e na família e, ao mesmo tempo, aponta para os perigos que essas mudanças podem acarretar para a estrutura social e para o papel de reprodutora física e ideológica ocupado pela mulher na família.

A constituição de uma subjetividade autônoma ainda encontra sérios obstáculos para o gênero feminino, na medida em que representa a negação de estruturas simbólicas que o faz dependente do outro sexo. Ao mesmo tempo, que busca a autonomia, sente-se responsável pelo bem comum familiar. Cria-se uma luta entre os diferentes membros da família em busca das próprias individuações, cabendo à mãe/esposa o papel de zelar pelo coletivo; já a realização pessoal/profissional, só é aceita quando não acarretar problemas para o bom andamento da casa. Por isso muitas mulheres desistem da atividade profissional e só se encaminham para esta por necessidade financeira, ou quando os filhos não precisam mais de assistência diuturna; no entanto, continuam se responsabilizando pelo bom
andamento do lar.

A ambigüidade faz parte da constituição da representação simbólica da mulher moderna. Na verdade, essa mulher não quer se desfazer do espaço da casa, muitas vezes ela quer a proteção que uma relação de dependência pode trazer. Ao mesmo tempo, quer 
acrescentar as formas simbólicas que sustentam ideologicamente a formação de uma sociedade baseada na autonomia do sujeito individual. A ambigüidade não está contrapondo isto ou aquilo, mas está colocando a junção das duas possibilidades.

Ambigüidade não é falha, defeito, carência de um sentido que seria rigoroso se fosse unívoco. A ambigüidade é a forma de existência dos objetos da percepção e da cultura, percepção e cultura que são também ambíguas, constituídas não de elementos ou partes separáveis, mas de dimensões simultâneas, que, como dizia ainda Merleau-Ponty, somente serão alcançadas por uma racionalidade, para além do intelectualismo e do empirismo. (Chauí1986:123)

A ambigüidade é vista como possibilidade de ultrapassagem do passado e de reconstituição de um futuro diferente do presente. A maternidade compartilhada e a divisão das tarefas de reprodução da vida cotidiana representam a construção de novas bases para o casamento e, conseqüentemente, para a estrutura familiar, permitindo a cada membro da família um desenvolvimento enquanto ser autônomo.

Para que isso seja possível de se concretizar é necessário que novas relações sociais, que incluam a mudança nas relações de gênero, se coloquem como possibilidades de realização. Isto implica a revisão do conceito de feminino ligado a um dos lados da dicotomia razão/emoção e a desnaturalização das funções de reprodução da cotidianidade doměstica. Parir é ainda uma função ligada diretamente ao sexo feminino; extrapolar essa característica para as funções de maternagem e domesticidade é uma criação ideológica que, até hoje, vem cumprindo a função de reproduzir o sistema capitalista de forma satisfatória para os dominantes.

Depois de percorrer as diversas estruturas familiares ao longo da história da humanidade, podemos concluir que algumas funções permanecem, outras são explicitadas e algumas silenciadas. A constātação que nos diz respeito aqui é a de ser a família o lugar da afetividade e da intimidade, como já salientado, mas é também o lugar da violência, algo que durante muito tempo foi alvo de um silenciamento cúmplice entre todos os seus membros, e, o que é mais importante, foi apagado das instituições sociais. 
Todo discurso, como vimos, carrega uma contraditoriedade dialética insuperável: tende à generalização a partir de expressões da vida cotidiana e busca uma determinação individualizante que cria novas palavras e novos sentidos. Essa é a base da fecundidade do discurso e, concomitantemente, a dificuldade a ser enfrentada pela análise do discurso.

Sintetizando esse ponto, pode-se afirmar que o discurso depende das transformações da vida social e da sua própria autoTegalidade. Ao mesmo tempo é importante ressaltar que, por ser generalizado em todos os aspectos das relações sociais, pois ocupa lugar primordial na vida cotidiana, o discurso reage aos mínimos abalos do ser social, com atos expressivos imediatos.

Com as marcas de discriminação e violência contra a mulher fazendo a história do Brasil, dois jornais - um de circulação nacional e outro, o de maior penetração no Estado de Alagoas - instituem o Caderno Mulher, depois da universalização da discussão do novo movimento feminista, surgido nos anos 60, transformando suas colunas em verdadeiros veículos de reprodução da moral vigente ao não discutirem os temas pertinentes às contradições da condição feminina, silenciando sobre a gênese da discriminação, o que contribui para que a violência em relação à mulher continue a ser praticada, muitas vezes com requintes de crueldade ${ }^{7}$. A não-discussão da estrutura familiar de base patriarcal contribui para a reprodução do ideário do machismo, que determina a posição de subalternidade do gênero feminino e permite que os companheiros tratem as mulheres como seres desqualificados, necessitando de "correção" para não perder o rumo, justificando tanto a violência física como a psicológica e reforçando o poder do marido na relação conjugal.

Por outro lado, quando os problemas são enfrentados pelos jornais, o tratamento a eles dispensados é superficial, gerando um discurso ambíguo, que simultaneamente defende as conquistas realizadas e dá conselhos de como se vestir para não ser assediada, estabelecendo uma relação direta entre o comportamento feminino e os atos de violência. Com isso, embora evidentemente condenem a violência, ao final acabam por justificá-la.

7 No mês de agosto de 2000, em Maceió, três homens estupraram uma mulher e arrancaram-lhe os olhos. 
Outra característica de ambos os jornais se refere à crítica explícita e implícita, ao dito e ao não-dito, dos discursos em relação ao movimento feminista. Como foi salientado, as feministas são vistas como mulheres sem equilíbrio, raivosas e que, no ímpeto de "conscientizar as mulheres", acabam por afastá-las de uma verdadeira emancipação que, para estes jornais, deve estar direcionada para a moda, beleza, consumo, pois metade dos espaços dos cadernos é preenchida por matérias, propagandas e receitas, reforçando o ideário da futilidade e de compulsividade em relação ao corpo e às compras.

Complementando o ideário, está o papel da mulher mãe, exaltado continuamente por discursos que as concebem como únicas capazes de prevenir os filhos dos perigos da sociedade contemporânea, assegurando, por isso, que o lugar de guardiã do lar continua sendo privilégio feminino. Em um ano de divulgação, apenas um editorial do JB aborda o problema da divisão de tarefas domésticas, mesmo assim acentuando apenas o acúmulo de obrigações das mulheres, o que remete a pelo menos duas interpretações: 1- há necessidade de auxílio de alguém; 2- Para solucionar o acúmulo, as que podem deixem o trabalho e dediquem-se só ao lar.

$\mathrm{Na}$ verdade fala-se de mudança para que, com as modificações do mundo moderno, a essência das relações familiares permaneça a mesma.

Finalmente, para concluir, gostaríamos de deixar bem claro não serem as feministas ou o movimento feminista os responsáveis pela discriminação e violência contra a mulher, como alguns querem salientar, ao atribuir às reivindicações e mudanças de comportamento das mulheres a causa da crise de identidade dos homens, tornando-os mais violentos, como se elas fossem as provocadoras do assédio e do comportamento violento. Esse tipo de discurso tem como objetivo fazê-las calar e voltar ao lugar de antes, tão ou mais discriminador e violento como o de agora, pois as únicas saídas eram a submissão ou a morte.

Podemos finalmente concluir que os Cadernos Mulher aqui analisados cumprem a função de silenciamento do ideário feminista, embora sejam fruto desse movimento, reforçando as relações patriarcais. Evidencia-se, então, um discurso moderno cujas mudanças tecnológicas e discursivas são ressaltadas, mas que efetivamente 
reforça a manutenção da naturalização do papel da mulher, pois continua a enaltecer as capacidades femininas - gestar e aleitar, como geradoras do seu comportamento, contribuindo para a formatação do papel da mulher e, conseqüentemente, reforçando a possibilidade da violência geral e doméstica. Há, enfim, necessidade de romper com esse círculo vicioso que transforma, ao mesmo tempo, as mulheres em vítimas e responsáveis pela violência.

\section{REFERÊNCIAS BIBLIOGRÁFICAS}

ARISTÓTELES. Poética. Tradução de Eudoro de Souza. Rio de Janeiro: Globo [s.d.].

BOURDIEU, Pierre. La domination masculine. Paris: Seuil, 1998.

CHAUÍ, Marilena. Conformismo e resistência. São Paulo: Brasiliense, 1986.

COURTINE, JJ. Analyse du discours politique. Paris: Larouse, 1981.

LEMENHE, Maria Auxiliadora. Família, tradição e poder. São Paulo: Annablume/ UFC,1995.

LUKÁCS, Georg. O Trabalho. Tradução de Ivo Tonet. Maceió: 1997, (mimeo.).

MAGALHÃES, Belmira et al. Da linguagem ao poder. Maceió: Edufal, 1997

MAGALHÃES, Belmira et al. Magistério: reprodução da discriminação feminina. Curitiba: HD livros, 1996

MALDIDIER, Denise. L'inquiétude du discours. Paris: Éditions des Cendres, 1990

MARX, Karl. Glosas críticas marginais ao artigo. Tradução de Ivo Tonet. Revista Praxis, Belo Horizonte: Projeto Joaquim de Oliveira, n. 5, 1995.

MAZZEO, Antonio Carlos. Estado e burguesia no Brasil: origens da autocracia burguesa. Belo Horizonte: Oficina de Livros, 1989.

MELLO, João Manuel Cardos de. O capitalismo tardio. São Paulo: Brasiliense, 1988.

MÉSZÁROS, István. Filosofia, ideologia e ciência social: ensaios de negação e afirmação. São Paulo: Ed. Ensaio, 1993. 
ORLANDI, E As formas do silencio :no movimento dos sentidos 4.ed. São Paulo: Unicamp,1997.

ORLANDI, E. Interpretação: autoria, leitura e efeitos do trabalho simbólico. São Paulo: Vozes, 199

PÊCHEUX, M. O discurso: estrutura ou acontecimento. Trad. Eni Orlandi. Campinas: Pontes, 1990.

PEREIRA, Carlos Alberto [et al.] (org.) Linguagens da Violência. Rio de Janeiro: Rocco, 2000.

PRATES E SILVA, Regina. Os gregos e a concepção da mulher como homem inacabado. In: SILVA (org.). Mulheres em seis tempos. Araraquara: UNESP, 1991

TONET, Ivo. Mercado e liberdade. Maceió: Edufal, 1997.

VAISMAN, Ester. A ideologia e sua determinação ontológica. Ensaio, S. Paulo, n. 17-18, p. 399-444, 1989. 